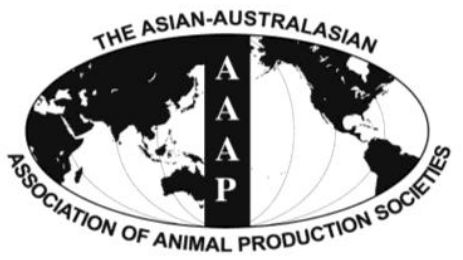

Asian-Aust. J. Anim. Sci.

Vol. 25, No. 4 : 584 - 591

April 2012

www.ajas.info

http://dx.doi.org/10.5713/ajas.2011.11051

\title{
Free Range Hens Use the Range More When the Outdoor Environment Is Enriched
}

\author{
T. A. D. Nagle ${ }^{1,3, *}$ and P. C. Glatz ${ }^{2}$ \\ ${ }^{1}$ Redlands Research Station, DEEDI, P.O. Box 327, Cleveland, QLD 4163, Australia
}

\begin{abstract}
To evaluate the role of using forage, shade and shelterbelts in attracting birds into the range, three trials were undertaken with free range layers both on a research facility and on commercial farms. Each of the trials on the free range research facility in South Australia used a total of 120 laying hens (Hyline Brown). Birds were housed in an eco-shelter which had 6 internal pens of equal size with a free range area adjoining the shelter. The on-farm trials were undertaken on commercial free range layer farms in the Darling Downs in Southeast Queensland with bird numbers on farms ranging from 2,000-6,800 hens. The first research trial examined the role of shaded areas in the range; the second trial examined the role of forage and the third trial examined the influence of shelterbelts in the range. These treatments were compared to a free range area with no enrichment. Aggressive feather pecking was only observed on a few occasions in all of the trials due to the low bird numbers housed. Enriching the free range environment attracted more birds into the range. Shaded areas were used by $18 \%$ of the hens with a tendency $(p=0.07)$ for more hens to be in the paddock. When forage was provided in paddocks more control birds (55\%) were observed in the range in morning than in the afternoon (30\%) while for the forage treatments $45 \%$ of the birds were in the range both during the morning and afternoon. When shelterbelts were provided there was a significantly $(\mathrm{p}<0.05)$ higher $\%$ of birds in the range $(43 \%$ vs. $24 \%)$ and greater numbers of birds were observed in areas further away from the poultry house. The results from the on-farm trials mirrored the research trials. Overall 3 times more hens used the shaded areas than the non shaded areas, with slightly more using the shade in the morning than in the afternoon. As the environmental temperature increased the number of birds using the outdoor shade also increased. Overall 17 times more hens used the shelterbelt areas than the control areas, with slightly more using the shelterbelts in the afternoon than in the morning. Approximately 17 times more birds used the forage areas compared to the control area in the corresponding range. There were 8 times more birds using a hay bale enriched area compared to the area with no hay bales. The use of forage sources (including hay bales) were the most successful method on-farm to attract birds into the range followed by shelterbelts and artificial shade. Free range egg farmers are encouraged to provide pasture, shaded areas and shelterbelts to attract birds into the free range. (Key Words : Poultry, Enrichment, Free Range, Shelter Belt, Forage, Feather Pecking)
\end{abstract}

\section{INTRODUCTION}

The barren environment of free range paddocks is often identified as a major cause of poor use of the range by laying hens. In addition aggressive behaviour and cannibalism in laying hens (Klemm et al., 1995; Elliot, 1996; Ambrosen and Petersen, 1997) is negatively correlated with foraging and exploratory behaviours (Blokhuis and Van der Haar, 1992; Huber-Eicher and

\footnotetext{
* Corresponding Author: Tanya Nagle. Tel : +61-7-3824 9534, Fax : +61-7-3286-3094, E-mail : Tanya.Nagle@deedi.qld.gov.au

2 SARDI-PPPI, University of Adelaide, JS Davies Building, Roseworthy Campus, Roseworthy SA 5371, Australia.

$3{ }^{\circ}$ The State of Queensland (through the Department of Employment, Economic Development and Innovation) 2011. Submitted Mar. 1, 2011; Accepted Apr. 11, 2011; Revised May 11, 2011
}

Wechsler, 1998). Even though feather pecking is reduced when the hens use the free range frequently, feather pecking remains a serious problem on free range farms (Bestman and Wagenaar, 2003; Bestman and Wagenaar, 2006). Reduced feather pecking occurs when birds are reared in the same facility, stocking density is low, high quality litter is used and perches are provided (Bestman and Wagenaar, 2003; Bestman and Wagenaar, 2006; Knierim et al., 2008).

The work in the European Union suggests therefore that feather pecking in free range flocks is greatest when a low \% of birds used the range (thus a higher stocking density in the shed), and that enriching the range with trees and shaded areas may encourage more birds to use it (Bestman and Wagenaar, 2003; Nicol et al., 2003; Zeltner and Hirt, 2003). Therefore environmental enrichment in the range may reduce feather pecking in free range systems by 
redirecting beak-related activities towards other substrates in the range. There is potential to improve the ranging ability of birds in free range systems and get the birds out of the shed (where they tend to feather peck) by using shelterbelts and crop rotations (Miao et al., 2006), shade and sand baths. Improving the attractiveness of the range for birds is therefore an important aspect to investigate. Currently many range areas are just fenced open fields with hardly any cover. This does not allow the hen the opportunity to seek shelter from weather or predators, or make the free range area stimulating for the birds to use (Hegelund et al., 2002). Studies have shown that there is a positive relationship between the availability of overhead cover and the $\%$ of birds in the range (Hegelund et al., 2002; Bestman and Wagenaar, 2003; Nicol et al., 2003; Zeltner and Hirt, 2003). The enrichment of the range with shade and shelter and providing a variety of these facilities enables birds to meet their behavioural needs. Trees provide an area where birds can dust bathe (Dawkins, 2003), and seek shade and protection from predators. More birds use the range area when cloud cover is prevalent (Hegelund et al., 2002) and when man made shade areas are provided. The use of the range decreases as the flock size increases. A greater $\%$ of the birds use the range in small flocks compared to larger flocks (Hirt et al., 2000; Hegelund et al., 2002). Hens in the range usually remain close to the poultry house (Furmetz et al., 2005) and leave the area denuded of forage. However, when trees or shrubs or shaded areas are provided about $75 \%$ of hens in larger flocks will use the range (Bestman and Wagenaar, 2003). Nevertheless poor use of the range by hens remains a major issue in all free range systems. Birds are unable to hide from predators if there is no overhead protection provided by trees or other shaded areas.

The objective of this study was to evaluate the effectiveness of enrichment methods to attract birds into the range in sub tropical regions in Queensland and a Mediterranean climate in South Australia.

\section{MATERIALS AND METHODS}

\section{Research trials}

The free range research facility in South Australia comprised an eco shelter divided into 6 experimental units each holding 20 birds. The birds in each experimental unit had access to a $726 \mathrm{~m}^{2}$ paddock adjoining the shelter. Hyline Brown layers were used in all trials.

Experiment 1 - Shade : There were 2 treatments; i) control group, and ii) treatment group allowed access to shade in the range. There were 3 replicates of each treatment. The shade $(3 \mathrm{~m} \times 2 \mathrm{~m} \times 1 \mathrm{~m})$ was provided by waterproof shade cloth suspended from 4 posts. The control hens were not provided outdoor shade while the treatment hens were provided a shaded area located $10 \mathrm{~m}$ and $20 \mathrm{~m}$ from the shed. Birds were examined over $32-44$ weeks to determine if they spent a greater $\%$ of time in the range and the subsequent influence on bird condition, feather pecking, cannibalism and production.

Video recordings were made of hens from each replicate for a $1 \mathrm{~h}$ period in the morning and afternoon resulting in 12 $\mathrm{h}$ of video tape being assessed per trial.

Experiment 2 - Shelterbelts : There were 2 treatments; i) control group, and ii) group allowed access to moveable shelterbelt (shrubs in pots). The treatment hens were provided a shelterbelt $10 \mathrm{~m}$ and $20 \mathrm{~m}$ from the poultry house. The shelterbelt $6 \mathrm{~m}^{2}(3 \mathrm{~m} \times 2 \mathrm{~m}=1 \times \mathrm{b})$ consisted of a range of sizes of trees in pots (small ( $1 \mathrm{~m}$ high), medium (2 $\mathrm{m}$ high) and large (3 $\mathrm{m}$ high) $)$ as well as shrubs $1 \mathrm{~m}$ in height. There were 3 replicates of each treatment. Birds were examined over 24-32 weeks to determine if they spent a greater $\%$ of time in the range and subsequent influence on bird condition, feather pecking, cannibalism and production. Video recordings were made of hens from each replicate for a $1 \mathrm{~h}$ period in the morning and afternoon resulting in $12 \mathrm{~h}$ of video tape being assessed per trial.

Experiment 3 - Forage: There were 3 treatments provided in the range, no pasture (control); vetch pasture and wheat pasture. Over the period 58-70 weeks birds were allowed access to the range $\left(726 \mathrm{~m}^{2} /\right.$ replicate $)$ and measurements were made on production, feather score and $\%$ of birds foraging. Video recordings were made of hens from each replicate for a $1 \mathrm{~h}$ period in the morning and afternoon resulting in $12 \mathrm{~h}$ of video tape being assessed per trial.

\section{Statistical analyses}

All data from the three research trials were analysed using ANOVA in Systat software (Wilkinson, 1996). Bonferroni's post hoc was used to separate means only if significant main effects were detected by analysis of variance. Bonferroni's post hoc test is a multiple comparison test based on Student's t statistic and adjusts the observed significance level when multiple comparisons are made.

\section{On-farm trials}

The on-farm trials were run on commercial free range layer farms on the Darling Downs in Southeast Queensland. All farms were under the same ownership. Birds experienced the same management practices and were provided the same feed, rearing conditions and all birds were housed in naturally ventilated sheds. The strains of birds used were Hyline Brown, Bond Black and Bond White depending on the trial.

Trial 1 - Shadecloth trial on commercial farm : A total of 6,800 Hyline Brown hens (age range 22-52 weeks) were 
housed in 3 naturally ventilated sheds. Birds had access to shade in the range area. Another 6,700 hens (age range 2254 weeks) were housed in 3 similar sheds without access to shade. The shade areas (water proof cloth support by posts) were of differing sizes (average $35 \mathrm{~m}^{2}$ ) depending on the size of the flock in the shed and were $30 \mathrm{~m}$ and $60 \mathrm{~m}$ out from the shed. The trial was run during the winter period.

There were two treatments; i) hens with access to shadecloth shelters in the range area, and ii) hens without access to shade with three replicates of each treatment. Birds were monitored for 12 weeks to determine their use of the shade and influence on feather score and bird weight.

Trial 2 - Shelterbelt and summer shadecloth: A total of 2,000 Hyline Brown hens (age range 43.5-73.5 weeks) were housed in 2 naturally ventilated sheds and allowed access to shelterbelts in the range area. Another 3,000 hens (age range 35.5-55 weeks) housed in 2 naturally ventilated sheds did not have access to the shelterbelt and shade. The shade areas were of different area $\left(15-30 \mathrm{~m}^{2}\right)$ depending on the size of the flock in the shed and were $15 \mathrm{~m}$ and $30 \mathrm{~m}$ out from the shed.

There were two treatments; i) hens with access to shelterbelts in the range area, and ii) hens without access to shelterbelts with two replicates of each treatment. Birds were monitored for 15 weeks to determine if birds with access to the shelterbelt used the range more and the role of shade on feather score and bird weight.

At the same time two sheds (one with a shadecloth shelter and one without) continued to run through the summer period for comparison with the shadecloth trial.

Trial 3 - Forage trial on commercial farm : A total of 4,800 hens which included a mix of 3 strains Hyline Brown, Bond Black and Bond White (age range 22-48 weeks) were housed in 2 naturally ventilated sheds and had access to sorghum forage in the range area. Another 4,900 hens (age range 38-82 weeks) were housed in 2 naturally ventilated sheds without access to forage but with access to a hay bale in the range. The forage areas were approximately $35 \mathrm{~m}^{2}$, and were $12 \mathrm{~m}$ and $30 \mathrm{~m}$ out from the shed. Areas of the same size were pegged out in the range without shade with two of the four areas having access to a hay bale. Monitoring of birds included feather score, bird weight and temperature recording. The trial was run through winter.

There were three treatments; i) hens with access to forage in the range area, ii) hens without access to forage, and iii) hens with access to a hay bale in the range area with 2 replicates of each treatment. The size of the forage area was dependant on the number of hens in the flock/shed and was positioned $12 \mathrm{~m}$ and $30 \mathrm{~m}$ out from the shed. Birds were examined for 14 weeks to determine if birds with access to shade used the range more and influence on feather score and bird weight.

Feather scores were scored using the method described by Tauson et al. (2005). Cameras recorded daily ( $1 \mathrm{~h}$ am and $1 \mathrm{~h} \mathrm{pm}$ ) the use of enriched and non enriched areas in all trials. Trends were looked at in the data using changes over time because of the different ages of the birds used.

\section{RESULTS}

\section{Trial 1 - Shadecloth}

Under research and commercial conditions, no significant difference was found in feather condition of birds provided shade or given no shade. Poor feather condition was observed at the base of the tail and vent of all birds irrespective of whether they were provided shade or no shade. The weight of the birds was also similar regardless of access to shade in the range area.

In the research trial in the morning shaded areas were visited by $18.6 \%$ of the hens (Table 1 ) with a tendency $(\mathrm{p}=$ 0.07 ) for more hens to be in the paddock; $43 \%$ for paddocks with shade compared to $25 \%$ for the paddocks with no shade provided. In the afternoon there were no differences between treatments for hens that used the range $30 \%$ for shade treatment vs. $40 \%$ no shade; $\mathrm{p}=0.49)$. Only $11 \%$ of hens used the shade in the afternoon (Table 1). There was no significant difference $(p=0.22)$ for $\%$ of hens in the shade $10 \mathrm{~m}$ from the shelter vs. those $20 \mathrm{~m}$ from the shelter. The provision of shaded areas in the free range attracted some additional hens into the range but other attractants are needed to encourage more hens into the paddocks, particularly during the summer season.

On the commercial farm the trend was for more birds to use the shaded areas in the range than the non shaded areas

Table 1. The $\%$ of birds in the shelter, in the range, using the shade and not in the shade for the shade and no shade treatments

\begin{tabular}{llcccc}
\hline Treatment & Time of day & Birds in range (\%) & Birds in shade (\%) & Birds not in shade (\%) & Birds in shelter (\%) \\
\hline Shade & Morning & 43.2 & 18.6 & 61.8 & 38.2 \\
& Afternoon & 30.7 & 11.1 & 41.9 & 58.1 \\
p value & & 0.36 & 0.27 & 0.30 & 0.30 \\
No-shade & Morning & 24.7 & - & - & 75.3 \\
& Afternoon & 40.2 & - & - & 59.8 \\
p value & & 0.13 & & & 0.13 \\
\hline
\end{tabular}

$\mathrm{p}=$ Probability value determined in the analysis of variance. 


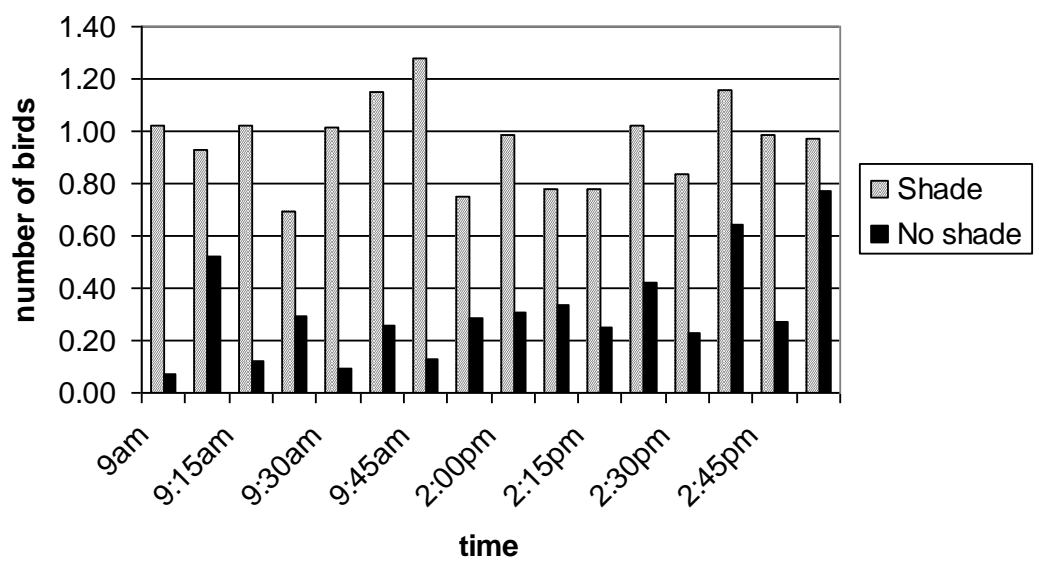

Figure 1. Average number of birds in shade and non shade areas over a day.

in the corresponding ranges (Figure 1). Overall 3 times more hens used the shaded areas than the non shaded areas, with slightly more using the shade in the morning than the afternoon.

The temperature inside the sheds, and to a lesser extent in the range area, was positively correlated with the number of birds using the shaded area. As the temperature increased the number of birds using the shade also increased. Two sheds (one with outdoor shade and one without) continued to be monitored over the summer months to compare with the results received during the winter. The trend over a summer day was for six times the number of birds to use the shaded area than the corresponding non shaded area with more birds using the shaded areas in summer than winter and very few birds using the non shaded areas in summer (Figure 2).

\section{Trial 2 - Shelterbelt}

There was no significant effect on bird weight and feather score of hens whether they were provided with shelterbelts or no shelterbelts in the range in both trials. Egg weight and rate of lay were measured in the research trial were also not affected.

In the research trial there was a significantly $(\mathrm{p}<0.05)$ higher $\%$ of birds in the range when provided a shelterbelt compared to no shelterbelt and this was consistent for the morning and the afternoon (Table 2). The number of birds $20 \mathrm{~m}$ from the shelter was higher (although not significant, $\mathrm{p}=0.12$ ) for birds provided a shelter belt compared to no shelter belt.

Under commercial conditions the trend was for more birds to use the shelterbelt areas in the range than the non shaded areas in the corresponding ranges. Overall 17 times more hens used the shelterbelt areas than the non shaded areas, with slightly more using the shelterbelts in the afternoon than the morning (Figure 3).

\section{Trial 3 - Forage trial}

No difference in feather cover of the treatment groups was observed in the research trial. The first shade trial

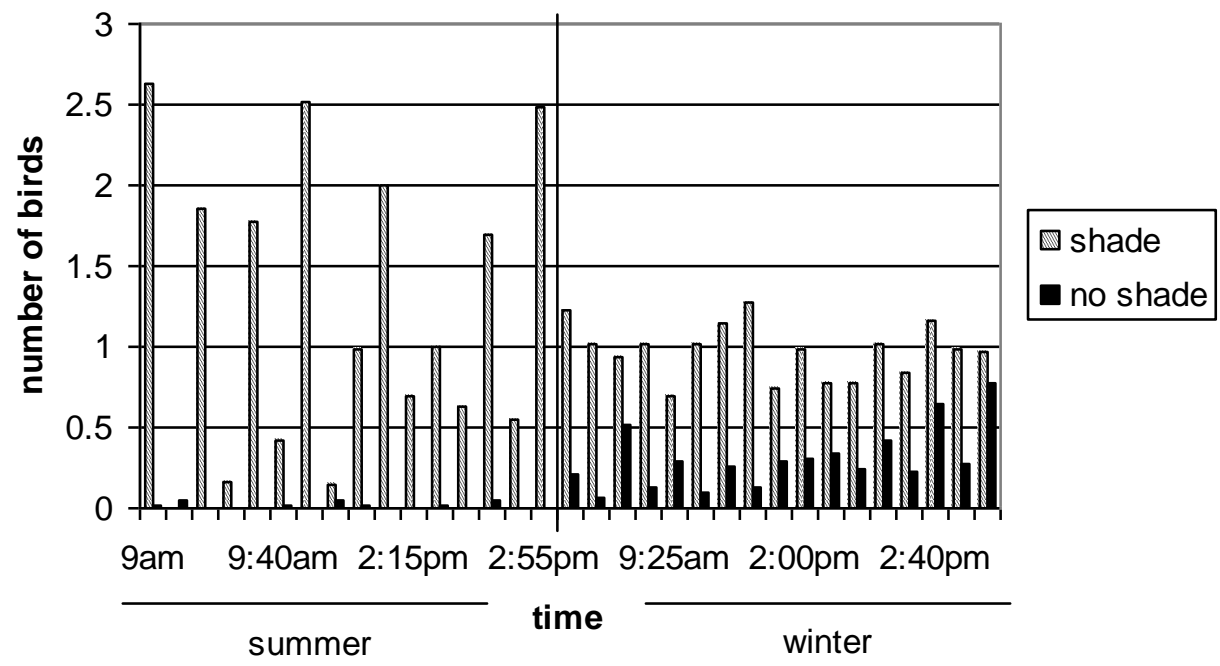

Figure 2. Average number birds in shade and non shade areas over a summer and winter day. 
Table 2. The $\%$ of birds in range when provided a shelterbelt or no shelterbelt in the range

\begin{tabular}{|c|c|c|c|c|}
\hline Time & Treatment & Birds in range $(\%)$ & $10 \mathrm{~m}$ from shelter $(\%)$ & $20 \mathrm{~m}$ from shelter $(\%)$ \\
\hline \multirow[t]{2}{*}{ Morning } & Control & 22.115 & 46.020 & 20.530 \\
\hline & Shelter belt & 40.833 & 47.468 & 40.994 \\
\hline \multirow[t]{2}{*}{ Afternoon } & Control & 27.628 & 45.999 & 29.184 \\
\hline & Shelter belt & 45.385 & 38.572 & 45.189 \\
\hline Source of variation & & $\mathrm{p}$ value & $\mathrm{p}$ value & $\mathrm{p}$ value \\
\hline Time & & 0.569 & 0.526 & 0.576 \\
\hline Treatment & & 0.049 & 0.670 & 0.122 \\
\hline Timextreatment & & 0.956 & 0.528 & 0.846 \\
\hline \multicolumn{5}{|l|}{ Time of day } \\
\hline Morning & & 31.474 & 46.744 & 30.762 \\
\hline Afternoon & & 36.506 & 42.285 & 37.186 \\
\hline $\mathrm{p}$ value & & 0.588 & 0.512 & 0.581 \\
\hline SEM & & 4.502 & 3.302 & 5.645 \\
\hline \multicolumn{5}{|l|}{ Treatment } \\
\hline Control & & 24.872 & 46.010 & 24.857 \\
\hline Shelter belt & & 43.109 & 43.020 & 43.091 \\
\hline $\mathrm{p}$ value & & 0.040 & 0.661 & 0.108 \\
\hline SEM & & 4.502 & 3.302 & 5.645 \\
\hline
\end{tabular}

observed poor feather condition at the base of the tail and vent of all birds. This finding was also shown in the forage treatment. In addition, in the research trial the feather score for the left and right legs for all treatments was poor toward the end of the trial. In the commercial farm trials the birds with access to forage had an overall lower average feather score of 1 compared to birds without access to forage at 14 weeks. Live weight was similar for both treatments in each trial.

The work undertaken in the research trial found that the $\%$ of control birds in the range was greater $(54 \%)$ in morning than the afternoon (30\%) while for the pasture treatments about $45 \%$ of the birds were in the range both during the morning and afternoon (Table 3). A higher $\%$ of birds ranged within $20 \mathrm{~m}$ of the shelter in the morning compared to in the afternoon.

In the commercial on-farm trials, approximately 17 times more birds used the forage areas compared to the same area of no shade in the corresponding range, with 8 times more birds using the hay bale enriched area compared to the area of no shade (Figure 4). The birds tended to use the areas throughout the day with little difference between morning and afternoon. Over the 14 weeks of the trial the number of birds using the forage and hay bale areas decreased, possibly in line with the decrease in the availability of forage and hay (Figure 5).

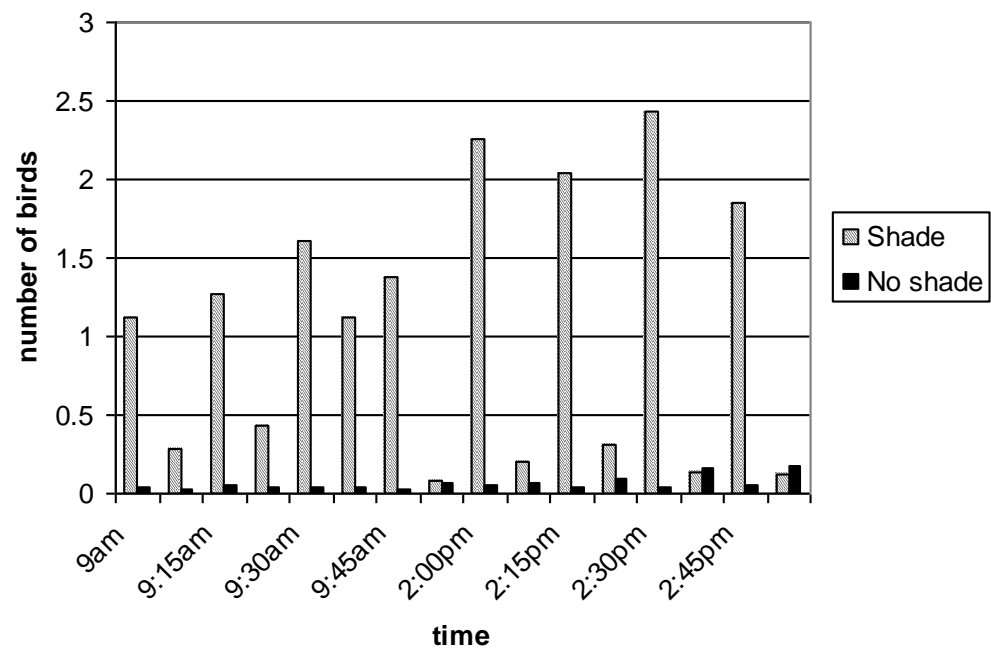

Figure 3. Average number of birds in shelterbelt shade and non shade areas over a day. 
Table 3. The $\%$ of birds in the range $10 \mathrm{~m}$ and $20 \mathrm{~m}$ from shelter for birds provided no pasture (control), vetch pasture and wheat pasture

\begin{tabular}{llccc}
\hline Time of day & Treatment & Birds in range $(\%)$ & $10 \mathrm{~m}$ from shelter $(\%)$ & $20 \mathrm{~m}$ from shelter $(\%)$ \\
\hline Morning & Control & $53.6 \pm 0.006$ & $16.7 \pm 2.184$ & $36.9 \pm 2.190$ \\
& Vetch & $47.4 \pm 2.957$ & $24.2 \pm 3.522$ & $22.9 \pm 6.176$ \\
& Wheat & $45.2 \pm 2.328$ & $23.4 \pm 3.340$ & $22.1 \pm 0.810$ \\
Afternoon & Control & $30.6 \pm 2.146$ & $20.9 \pm 3.817$ & $14.8 \pm 1.885$ \\
& Vetch & $40.3 \pm 2.656$ & $26.6 \pm 4.753$ & $13.5 \pm 7.196$ \\
& Wheat & $47.1 \pm 4.150$ & $20.0 \pm 1.417$ & $27.0 \pm 2.733$ \\
Source of variation & & 0.005 & 0.849 & 0.042 \\
Time & & 0.377 & 0.091 & 0.233 \\
Treatment & & 0.010 & 0.705 & 0.049 \\
Timextreatment & & &
\end{tabular}

\section{DISCUSSION}

Aggressive feather pecking was only observed on a few occasions in all research trials. However it was clear that enriching the free range environment attracted more birds into the range. For example shaded areas were used by hens with a tendency for outdoor shade to attract more birds into other areas of the paddock. When forage was provided in paddocks in the research trial, there was a significant interaction (treatment $\times$ time of day) for $\%$ of birds using the paddocks. More control birds were observed in the range in morning than the afternoon in the research trial while for the pasture treatments a similar $\%$ of the birds were in the range both in the morning and afternoon. Control birds explored the range in the morning to access any food source that was available given no forage was provided near the house. Clearly forage availability has an impact on the $\%$ of birds using the range during the day.

When shelterbelts were provided there were a significantly higher $\%$ of birds in the range and greater numbers of birds were observed in areas further away from the poultry house. These findings support the work of Hegelund et al. (2002) who observed the number of birds visiting the outdoor range depends on the type of outdoor enrichment birds are provided. Zeltner and Hirt (2003) tried to determine the characteristics of enrichment facilities in the range which could encourage more hens into the range as well as improve the distribution of the hens. They found that hens not provided any overhead protection (trees, bushes, and artificial structures) are less likely to use the free range area. However, free range paddocks that are provided with a large variety of enrichment facilities appear to encourage more frequent use of these facilities. Hens prefer ranging in areas with trees and will either stay close to the house or seek tree cover. This supports the current findings where a greater number of birds ranged outside when provided shade or shelterbelts. The lack of aggression of the birds in the research trial is likely due to the small flock size. However in larger operations there is no guarantee that there would not be an outbreak of feather pecking and cannibalism even when the environment is enriched.

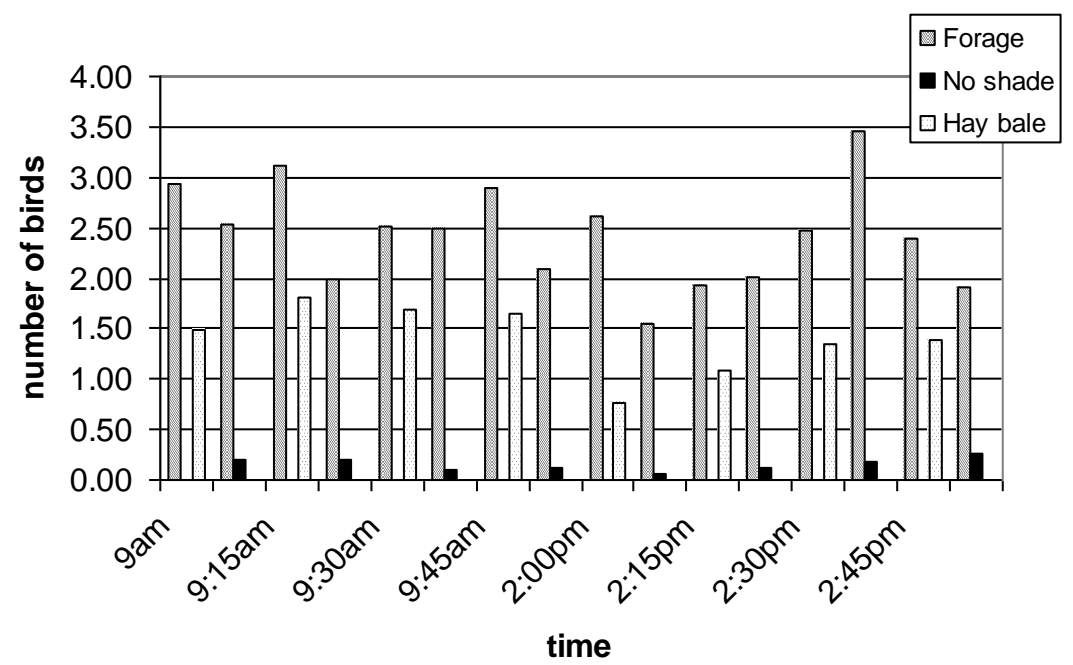

Figure 4. Average number of birds in forage, hay bale enriched and non shade areas over a day. 


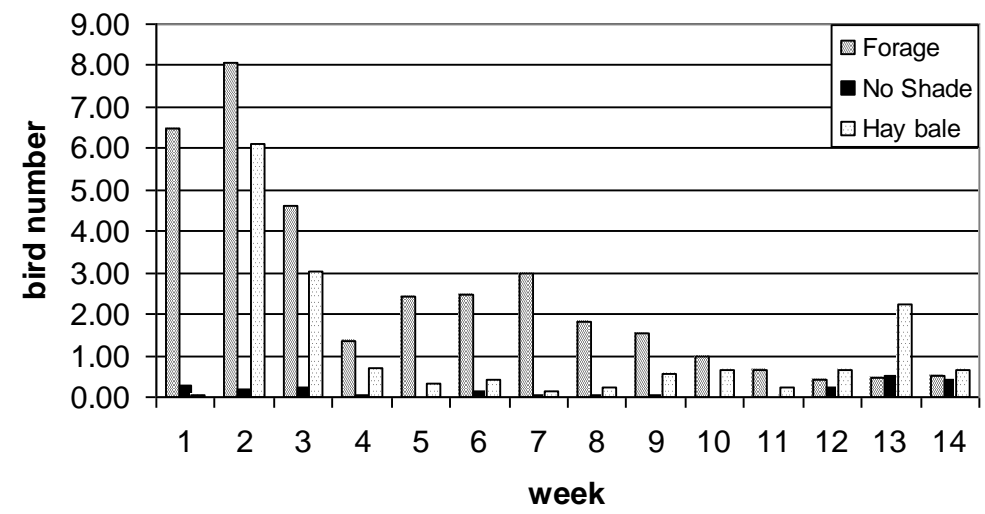

Figure 5. Weekly average number birds in forage, hay bale enriched and non shade areas over 14 weeks.

On the commercial farms the enrichment of the range areas with shadecloth, shelterbelts and forage attracted more birds to use these areas. The addition of hay bales to the range also proved to be a successful attractant for birds. Feather scores all showed a downward trend over the three trials regardless of the provision of shade with the back and tail areas most affected. The exception was the forage trial with birds having access to the forage having a feather score 1 point higher at the end of the 14 weeks. This result however is tempered by the fact that there were different breeds of hens used in the sheds in this trial (Hyline Brown, Bond Black and Bond White) which could have influenced the results. Bird weight was not affected by enrichment of the range areas.

Forage and hay bales attracted the most number of birds into the range. However, as their availability decreased the number of birds using the range dropped to a level in line with the areas with no forage or hay. This suggests in order to keep more birds on the range forage would have to be managed in a way to keep it available year round. If this is not possible (and with the climate in Australia it is more than likely not) hay bales can be added to the range as the forage decreases or until new forage has been grown with the same affect.

Shelterbelts and shadecloth shelters also attracted birds to the range. Through the summer months (temperatures on the range were commonly over $40^{\circ} \mathrm{C}$ ) when few birds ventured onto the range in the non shade areas, the shelterbelts encouraged a large number of birds out of their sheds into the range.

This work undertaken on commercial free range egg farms supports the results from the research trials with the recommendation that producers provide shade/enrichment in the range to attract more birds out of sheds and increase the use of these areas.

\section{CONCLUSION}

Free range egg farmers are encouraged to provide pasture, shaded areas and shelterbelts to attract birds into the free range.

Landscape architects should be utilised to design outdoor range areas which cater for the behavioural needs of birds and reduce feather pecking.

If unable to provide pasture, shelterbelts or shade cloth shelters, the provision of hay bales in the range areas proved to be an excellent alternative to attract birds from their sheds.

\section{ACKNOWLEDGEMENTS}

Acknowledgment is given to The Australian Poultry CRC for providing funds and the program management support from the late Assoc. Professor John Barnett, advice from Assoc. Professor Geoff Hinch and technical support from Mrs. B. Rodda, Mrs. S. Wyatt and Dr. Z. Miao at the PPPI and Mr. P. Zondagh, Mr. P. Kent and Mr. G. Collman from DEEDI. We thank Ms. A. Spencer from DEEDI for editorial assistance and the commercial free range producers in Southeast Queensland.

\section{REFERENCES}

Ambrosen, T. and V. E. Petersen. 1997. The influence of protein level in the diet on cannibalism and quality of plumage of layers. Poult. Sci. 76:559-563.

Bestman, M. W. P. and J. P. Wagenaar. 2003. Farm level factors associated with feather pecking in organic laying hens. Livest. Prod. Sci. 80:133-140.

Bestman, M. W. P. and J. P. Wagenaar. 2006. Feather pecking in organic rearing hens. Joint Org. Cong. Odense, 30-31 May 2006.

Blokhuis, H. J. and J. W. van der Haar. 1992. Effects of pecking incentives during rearing on feather pecking in laying hens. Br. Poult. Sci. 33:17-24.

Dawkins, M. S. 2003. Behaviour as a tool in the assessment of animal welfare. Zoology 106:383-387.

Elliot, M. 1996. Factors influencing feathering. Poult. Int. Nov: 80-81. 
Furmetz, A., C. Keppler, U. Knierim, F. Deerberg and J. Hess. 2005. Laying hens in a mobile housing system - Use and condition of the free-range area. In: Ende der Nische, Beiträge zur 8 (Ed. J. Hess and G. Rahmann). Wissenschaftstagung Ökologischer Landbau, Kassel, p. 313.

Hegelund, L., J. Kjaer, I. S. Kristensen and J. T. Sorensen. 2002. Use of the outdoor area by hens in commercial organic egg production systems. Effect of climate factors and cover. In: 11th European Poultry Conference - Abst. Arch. Geflügelkd 66:141-142.

Hirt, H., P. Hordegen and E. Zeltner. 2000. Laying hen husbandry: group size and use of hen-runs. In: Proc. 13th Int (Ed. T. Alföldi, W. Lockeretz and U. Niggli). IFOAM Sci. Conf., Basel, 363.

Huber-eicher, B. and B. Wechsler. 1998. The effect of quality and availability of foraging materials on feather pecking in laying hen chicks. Anim. Behav. 55:861-873.

Klemm, R., K. Reiter and H. Pingel. 1995. Investigations on feather pecking in Muscovy ducks. Arch. Gefluegelkd 59:99102.
Knierim, U., M. Staack, B. Gruber, C. Keppler, K. Zaludik and K. Niebuhr. 2008. Risk factors for feather pecking in organic laying hens-starting points for prevention in the housing environment. 16th IFOAM Org.Wld. Cong., Modena, Italy, June 16-20, 2008. Archived at http://orgprints.org/view/ projects/conference.html

Miao, Z. H., P. C. Glatz, Y. J. Ru, S. K. Wyatt and B. K. Rodda. 2006. Integration of hens into a crop and pasture rotation system in Australia-production and agronomic aspects. Aust. Poult. Sci. Symp. 18:94-99.

Nicol, C. J., C. Potzsch, K. Lewis and L. E. Green. 2003. Matched concurrent case-control study of risk factors for feather pecking in hens on free-range commercial farms in the UK. Br. Poult. Sci. 44:515-523.

Tauson, R., J. Kjaer, G. A. Maria, R. Cepero and K-E. Holm. 2005. Applied scoring of integument and health in laying hens. Anim. Sci. Pap. Rep. 23(Suppl.1):153-159.

Wilkinson, L. 1996. Systat 6.0 for Windows-Statistics. SPSS Inc., USA

Zeltner, E. and H. Hirt. 2003. Effect of artificial structuring on the use of laying hen runs in a free-range system. Br. Poult. Sci. 44:533-537. 